\title{
Fundamentos Biológicos da Saúde Pública e as Práticas Alternativas
}

\author{
F'ernando Dias de Avila-Pires
}

O nascimento da Biologia como disciplina individualizada e independente data do início do século XIX. O estudo de animais, plantas e microorganismos era parte da História Natural e caracterizava-se por ser empirico, descritivo e classificatório. Com Lamarck ganhou foros da Filosofia, isto é, passou a contar com um arcabouço conceitual teórico e fundamental. Para ele, o estudo das relações entre os organismos (taxonomia) e destes com o ambiente físico (que receberia de Haeckel, em 1866, a designação de Ecologia) constituíam a base das ciências da vida e estas incluíam o processo evolutivo ou transformista por herança de caracteres adquiridos proposto em 1809.

Theodor Georg August Roose parece ter sido o primeiro a utilizar o termo Biologia, o qual aparece no prefácio de sua obra intitulada "Grundzüuge von der Lehre von der Lebenkraft" (Branschweig, 1797). Em 1801 um crítico sugeriu, em "Neue algemeine deutsche Bibliotek", que ele designava com esse nome o que então se denominava fisiologia.

Em 1800 Karl Friedrick Burdach utilizou o mesmo termo em seu tratado "Propädeutik zum Studium der ge. samten Heilkunst: Ein Leitfaden akademischer Vorlesungen" (Leipzig).

Jean Baptiste de Monet, Chevalier de Lamarck também o usou cm "Hydro-geologie, ou Recherches sur I'Influence qu'ont les Eaux sur la Surface du Globe Terrestre" (Paris, dezembro de 1801 ou junho de 1802). Divide então. a "física da terra" em três partes: meterologia, hidrogeologia e biologia. Deixou inćdito un manuscrito sobre "Biologie. ou considerations sur la Nature". "Lehre von der Lebens et l'Origine de Corps Vivants". Em 1809, no texto de seu curso do Muśrum justificou a elevação do estudo dos anjmais à categoria de uma Filosofia Zoológica.

Em 1802, Gotticld Rcinhold Treviranus usou o termo no título de sua obra "Biologie oder Philosophie der lebenden Natur für Naturforscher und Arzte" (Gottingen, 6 vols., 1802-1822).

Com a teoria da evoluçĩo por seleçĩo Natural de Darwin (1850) a a consolidaçĩo da teoria celular (proposta em 1839 por Schwamn) no estudo da patologia celular de Virchow (1859), a Biologia ganhou dois novos paradıgmas 
e delimitou campos experimentais definidos. A citologia permitiu, por sua vez, o desenvolvimento da genética mendeliana, e o estudo experimental dos processos de variação, base da evolução orgânica. Com Claude Bernard surgiu a Filosofia Experimental e com Pasteur, a Microbiologia.

Independente em objetivos e métodos da antiga História Natural, a Biologia passa a oferecer a fundamentação científica à medicina que deixa, a partir de então, de ser empírica e artesanal para derivar soluçôes tecnológicas dos princípios básicos que definem a ciência biológica.

Ao dedicar-se às investigações sobre as doenças do bicho da seda, Pasteur decidiu" concentrer mes observations sur un point bien determiné, choisir le mieux possible et n'en abandonner l'étude qu'aprés avoir établi quelques principes que permissent d'avancer d'un pas sûr au milieu du dédale des idées préconçues.

Foram esses princípios que tornaram seu trabalho verdadeiramente científico e que permitiram sua extensão à pesquisa das doenças humanas e que o levaram a enunciar a teoria microbiana das infecções.

$\mathrm{Na}$ terceira fase de sua carreira, Pasteur dedicou-se ao problema da soroterapia e da vacinação.

As práticas antigas de variolização utilizadas na China e Turquia eram totalmente empíricas. Material colhido de pústulas de enfermos com sintomas benignos era inoculado em indivíduos sãos, na tentativa de protegê-los. Ao utilizálos na Inglaterra, no século XVIII, Jenner provocou uma revolução conceitual ao demonstrar, também com base em observações empíricas, que material obtido de um animal enfermo protegia o homem. Entretanto, somente após Pasteur ter oferecido uma explicação para o processo bioló. gico da imunização, pôde-se falar $\mathrm{cm}$ uma ciência que viria a ser a imunologia.

A ótica laica não distingue o cientista do inventor c não percebe que a invenção caracteriza-se por ser empírica e não por ser utilitária e que a ciência não é uma coleção de fatos, por mais abstrusos e técnicos que pareçam, mas uma explicação a que se chega utilizando um método próprio. Um último exemplo permitirá compreender melhor a distinção.

Desde a mais remota antiguidade a preservação $e$ conservação dos alimentos constitui um importante fator de sobrevivencia do homem. Incapaz de neutralizar certas toxinas que resultam da decomposição da matéria orgânica, - homem necessita de fontes alimentares abundantes e frescas. A acumulação de reservas para as épocas de escassez e para viagens longas, bem como para reduzir o tempo e a 
energia despendidos na busca do alimento e permitir o aumento populacional dependem da mvenção de métodos de desidratação, salga e defumação.

No século XVIII teve lugar uma long: polêmica sobre a questão da geração espontanea. exacerbada com a desco. berta e descricia dos microorganismos. No fim do século. um conferterro de Pars de nome Appert. estabelecido da Rue des Lombardes. produria alimentos em conserva: carnes. frutos e legumes. pelo antigo processo de aquecétos no interior de um recipiente de vidro hermeticamente fo. chado. Em 1811 publicou um livro no qual divulgava deta. thes do processo utiluado. do qual aliás. não se dizia autor. Estabeleceu uma pequena indústria em Massy (Seinect-Orse) e recebeu da marmha um prèmo de doze mil francos.

Em 1810 Gay-Lussac exammando as conservils de Apper concluiu que o ar encerado no vidro era distinto por faltar-lhe oxigeno. Lim 1837 Schwamn aquecen um pediço de came no intertor de um balio e fer chegar ate cle ar aquecedo a $350^{\circ}$. Como a carme naio se adulteron. ficou demonstrado que a calusa da puteliçio najo dependa do oxigentho e sim de um principlo encontrado no all atmos-

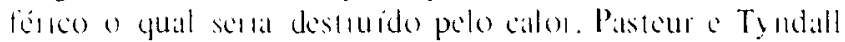

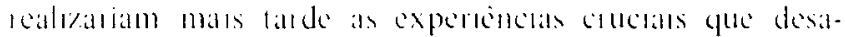

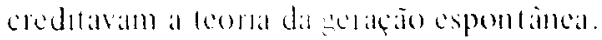

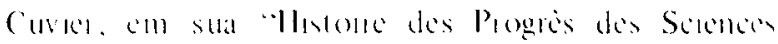

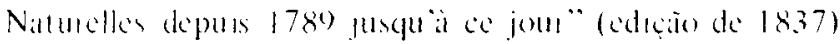

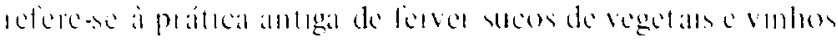

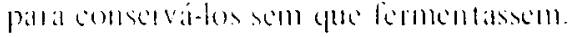

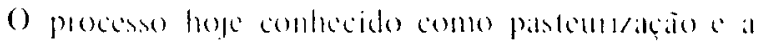

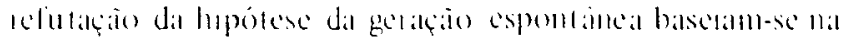

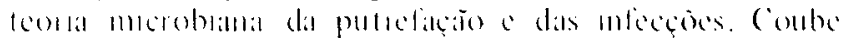

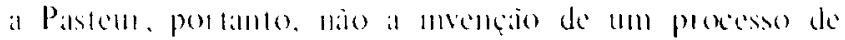

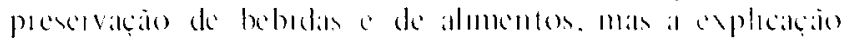

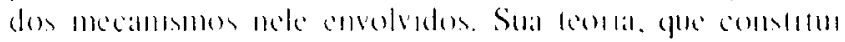

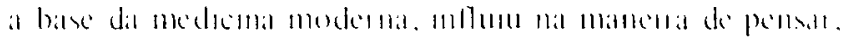

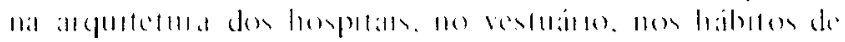

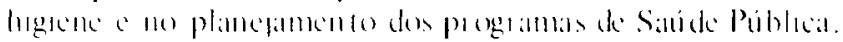

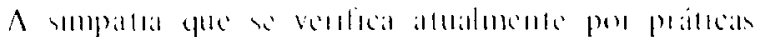

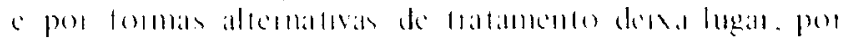

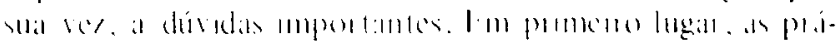

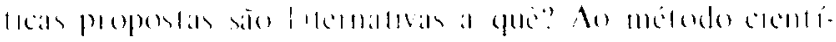

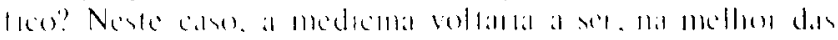

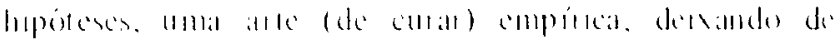

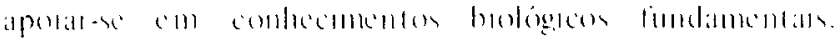

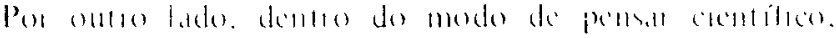

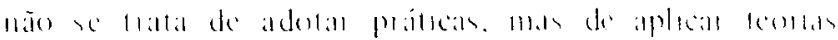

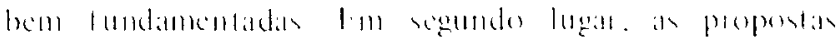

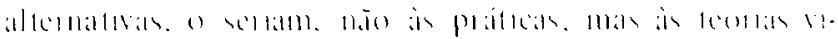


gentes? Neste caso, são necessários novos modelos das paradigmas que justifiquem as práticas propostas, ainda que com fins humanitários, econômicos e provisórios (faute de mieux...)

Bronowski, em "Ciência e Valores Humanos", cita W.K. Clifford, que argumentou: "Esta é a razão pela qual não devemos fazer mal, contando com o bem . . Seme. lhantemente, se eu acreditar em algo com provas insuficientes, não haverá grande dano pelo simples fato de acreditar; ... o perigo para a sociedade não reside simplesmente no fato de se poder acreditar em coisas erradas, embora isso já seja bastante, mas sim no fato de a sociedade poder se tornar crédula".

Bronowski acrescenta que "A prova da verdade é a evidência positivamente conhecida, e nenhuma oportunidade falaz nem razão de Estado podem justificar a mais pequena auto-ilusão a respeito". 